\title{
Participação e controle social no Brasil recente: influência do pensamento gramsciano
}

\author{
Participation and social control in contemporary Brazil: \\ influence of Gramsci's thought
}

Teresa Cristina Coelho Matos*

Maria D'Álva Macedo Ferreira**

\begin{abstract}
Resumo - Este artigo aborda sobre os momentos históricos em que o diálogo teórico e intelectual do pensador marxista, Antônio Gramsci, encontra materialidade no contexto da realidade brasileira recente, com o olhar voltado para a relação entre Estado e Sociedade focalizando o controle do aparato estatal pela participação dos movimentos sociais. Nessa perspectiva, confere-se centralidade às concepções gramscianas de Estado, sociedade civil e hegemonia, tendo como ponto de partida da reflexão a promulgação da Constituição de 1988. Palavras-chave: participação; controle social; estado; sociedade civil; Antônio Gramsci.
\end{abstract}

Abstract - This article discusses the historical moments in which the
theoretical and intellectual thought of Marxist thinker Antonio Gramsci
is actualized in the context of recent Brazilian reality. Special attention
is given to the relationship between state and society, focusing on the
control of the state apparatus through the participation of social mo-
vements. From this perspective, the Gramscian concepts of state, ci-
vil society and hegemony take center stage, taking as the starting point
the promulgation of the 1988 Constitution.
Keywords: participation; social control; state; civil society; Antonio Gramsci.

\footnotetext{
* Assistente Social, Especialista em Gestão de Organizações Públicas e Sociais pela Universidade Estadual do Piauí - UESPI, Mestra e Doutoranda em Políticas Públicas pela Universidade Federal do Piauí - UFPI. Correspondência: Rua Domingos Mourão, 394, Bairro São João, Teresina-PI. CEP 64046-430. E-mail:<teresacristina88@gmail.com> ${ }^{* *}$ Assistente Social, Doutora em Serviço Social pela Pontifícia Universidade Católica de São Paulo-PUC e Professora do Departamento de Serviço Social e do Programa de Pós-Graduação em Política Públicas da Universidade Federal do Piauí - UFPI. Correspondência: Rua Nilo Soares da Silva, 1172, Bairro Ininga, Teresina - PI. CEP 64048570. E-mail: <mdalvaferreira@uol.com.br>
} 


\section{Introdução}

No Brasil, é com o advento da Constituição de 1988 que se abre caminho para o estabelecimento de nova base de relação entre Estado e sociedade. Nela, a participação passa a ser um direito garantido constitucionalmente e o controle social das ações estatais tem a possibilidade de se firmar como categoria sociopolítica, na perspectiva dos teóricos críticos de matriz gramsciana. Por essa linha de pensamento, o controle social pode ser exercido ora pelo aparato estatal, ora pela sociedade, dependendo da correlação de forças estabelecidas entre ambos. A influência do pensamento de Gramsci na análise e interpretação da realidade brasileira se dá a partir de 1960, numa conjuntura política favorável à difusão do pensamento socialista, sendo barrada com a implantação da Ditadura Militar, em 1964, e retomada na segunda metade dos anos 1970, com a abertura do processo de democratização decorrente da luta da sociedade contra a ditadura.

Este artigo aborda os momentos históricos em que o diálogo teórico e intelectual das ideias de Gramsci encontra materialidade no espaço operativo do Brasil recente, tendo como ponto de partida a promulgação da Constituição de 1988, que influenciou no processo de democratização do país, a participação social e o exercício do controle social.

Com esse propósito, inicia-se por uma apresentação das categorias teóricas formuladas por Gramsci para analisar a realidade social na qual se inseria. Segue trazendo-as para refletir sobre a situação brasileira, conferindo centralidade às concepções de Estado, sociedade civil e hegemonia, ancoradas nas contribuições de teóricos nacionais de tradição marxista que se debruçaram na interpretação das ideias de Gramsci, como Carlos Nelson Coutinho, considerado um de seus principais intérpretes no Brasil. Cabe ressaltar que os eventos socioeconômicos, políticos e culturais presentes na dinâmica da sociedade brasileira encontram explicação em outros estudos, fundamentados em variadas matrizes teóricas.

\section{O pensamento de Gramsci: influência na sociedade contemporânea}

No âmbito da teoria marxista, o pensamento de Gramsci tem sido amplamente interpretado por diversos teóricos. Essas vastas interpretações favoreceram a formação de um "senso comum" gramsciano, que ajuda na reflexão e explicação de realidades sociopolíticas em variados contextos geográficos (BIANCHI, 2008). Na realidade brasileira, a influência do pensamento de Gramsci tem sido pauta de estudiosos que se debruçam na interpretação dessa realidade, conferindo maior relevo, como mostra Simionatto (2011), aos trabalhos de Carlos Nelson Coutinho. 
Uma característica marcante do perfil intelectual de Antônio Gramsci (1891-1937), admitida por ele próprio, é a de ter uma formação polêmica em termos de intelectualidade, pois tinha dificuldade "até de pensar 'desinteressadamente'". Dizia ter como estímulo intelectual colocarse, do ponto de vista dialógico ou dialético, como um interlocutor ou adversário concreto diante de qualquer ordem de reflexão (GRAMSCI, 2005b, p. 462).

Gramsci é submetido à prisão política pelo regime fascista italiano em um cenário marcado por teorias e processos políticos em confronto. Durante o cárcere, produz um quadro interpretativo de política e sociedade em relação à transição de uma sociedade capitalista para outra socialista, por meio de um processo de superação dialética do pensamento marxista. Como sublinham Coutinho (1992) e Secco (2002), afasta-se, então, do momento econômico corporativo para dar ênfase ao ético-político. Propõe uma reforma intelectual e moral a partir da formulação de novas categorias conceituais de sociedade civil e de Estado, conceitos estes que, mesmo com a queda do socialismo, tornaram-se válidos para interpretar as realidades das sociedades capitalistas contemporâneas.

Na teoria desenvolvida por Karl Marx (1818-1883), no contexto da sociedade capitalista industrial, a concepção do Estado ideal, presente, principalmente, em Hobbes (1979), Locke (2001) e Rousseau (1978), é substituída pela concepção do Estado opressor, que atua como instrumento de dominação de uma classe por outra (MARX; ENGELS, 1999, p. 28). A sociedade civil é definida enquanto sociedade burguesa e entendida como estrutura na qual se expressam a produção e a reprodução da vida material, haja vista que, para Marx (1993, p. 53), "a sociedade civil abrange todo o intercâmbio material dos indivíduos [...]." Assim, em Marx, sociedade civil corresponde à estrutura econômica na qual as relações de produção se estabelecem. Daí deriva o Estado como instrumento de controle dos conflitos estruturais em favor da classe economicamente dominante.

Em Gramsci, que não deixou de lado a essência do pensamento de Marx sobre dialética, filosofia da práxis e humanismo, a concepção de Estado e de sociedade civil passa por uma revisão teórica de "conservação/ superação" da teoria marxiana, no panorama do capitalismo monopolista do século XX. Neste, o fenômeno estatal apresenta-se mais complexo pela emergência e intensificação de processos de socialização e de participação política não vivenciados nem por Marx nem por seus seguidores clássicos, Engels e Lenin (COUTINHO, 1992, p. 75).

A perspectiva atribuída ao Estado pelo marxismo clássico - de garantir a reprodução da ordem capitalista pela coerção é ampliada por Gramsci, que o concebe atuando tanto pelo uso dos aparatos coercitivos, para disciplinar e intimidar a ação reivindicatória e lutas sociais, quanto pela busca do consenso "espontâneo", quando age perante as massas populares para controlar o jogo de forças sociais. Direcionando-as, pois, para a 
manutenção da ideologia capitalista, valorizando o prestígio adquirido pela classe dominante em decorrência das posições e funções que ocupa no mundo da produção (GRAMSCI, 1982, p. 11). Indica, assim, que o conteúdo e o formato de intervenção estatal dependem da correlação de forças no seio da sociedade. Gramsci apresenta essa concepção de Estado no seu programa de estudo e a explicita, sinteticamente, em carta escrita no cárcere, em setembro de 1931:

Este estudo [...] leva a certas determinações do conceito de Estado que, habitualmente, é entendido como sociedade política (ou ditadura, ou aparelho coercitivo, para moldar a massa popular segundo o tipo de produção e a economia de um dado momento), e não como um equilíbrio da sociedade política com a sociedade civil (ou hegemonia de um grupo social sobre toda a sociedade nacional, exercida através das organizações ditas privadas, como a igreja, os sindicatos, as escolas, etc.), e é especialmente na sociedade civil que operam os intelectuais. (GRAMSCI, 2005a, p. 84).

Vê-se que duas das categorias do constructo teórico de Gramsci, hegemonia e sociedade civil, são centrais na composição da sua concepção de Estado ampliado. A categoria hegemonia não recebe um conceito explícito nos escritos do pensador, que o vai elaborando no processo de construção de sua obra, atribuindo-lhe o sentido de supremacia de uma classe por outra, não apenas por forças coercitivas, mas pelo caminho da direção intelectual e moral, pelo consenso. Compreende, pois, consenso como a forma de um grupo social imprimir ao outro seus valores, sua cultura e visões de mundo (CERRONI, 1982). Sociedade civil, para Gramsci, é o conjunto de organismos privados, "aos quais se adere voluntariamente", que funciona como espaço privilegiado de luta de classe e como base material para a conquista de hegemonia, ou seja, para a busca de direção política e consensos (COUTINHO, 1992, p. 74). É tida, assim, como campo de luta pelo poder e de busca por consensos entre as classes, dependendo da correlação de forças que, pendendo para a sociedade civil, favorece a conquista de sua hegemonia e viabiliza a garantia de seus interesses perante a intervenção do Estado.

Nesse sentido, Gramsci (1982) confere atenção aos intelectuais, considerando-os sob duas vertentes; a que os vincula às categorias preexistentes, como os eclesiais, juristas, filósofos, e outra, concebendo-os como "intelectuais orgânicos", que se vinculam a cada grupo social em luta por hegemonia. Esclarece que, quando conectados com a classe subalterna, os intelectuais orgânicos exercem o papel de contribuir na formação da homogeneidade e consciência dessa classe, para que, sob uma visão ética nova no campo econômico, social e político, exerça a função de classe dirigente e conquiste a posição de grupo hegemônico. Do mesmo modo, aqueles ligados organicamente à classe dominante do capitalismo imbuem-se da 
função intelectual de difundir a ideologia capitalista para promover um ambiente favorável à manutenção dos seus interesses e domínio em detrimento do conjunto da sociedade.

\section{Participação e controle social no Brasil recente, à luz do pensamento gramsciano}

A difusão do pensamento de Gramsci em vários países do mundo ocidental, incluindo o Brasil, alcança maior amplitude a partir de meados da década de 1970 (SECCO, 2002; SIMIONATTO, 2011). Essa circulação foi favorecida pela mobilização de atores sociais coletivos em torno do enfrentamento de uma conjuntura socioeconômica, marcada por conflitos decorrentes da queda da "era de ouro do capitalismo", cujo reflexo é evidenciado no Brasil pela "crise do milagre brasileiro" (SINGER, 1989).

A acolhida e espraiamento das ideias de Gramsci no Brasil acontecem em contextos políticos distintos. Inicia-se na década de 1960, quando a conjuntura política brasileira estava fortemente influenciada pela ideologia socialista. No entanto, sofre retração com a instauração da Ditadura Militar de 1964, cujo principal intento era barrar os ideais socialistas e fortalecer um capitalismo vinculado ao aparelho de Estado. É retomada, noutro momento, em meados da década de 1970, num cenário de abertura do processo democrático, fruto da luta política da sociedade contra a Ditadura Militar, capitaneada por intelectuais e acadêmicos de tradição marxista, por partidos políticos e movimentos sociais de esquerda (COUTINHO, 1992; SECCO, 2002; SIMIONATTO, 2011).

Focando os momentos históricos em que a categoria gramsciana de Estado ampliado passa do campo das ideias para o campo operativo na realidade brasileira, vale conferir atenção aos significados de hegemonia e democracia, de modo relacional, conforme Gramsci (1984, p. 183) os expressa:

Entre os muitos significados de democracia, parece-me que o mais realista e concreto é aquele que se pode deduzir em conexão com o conceito de 'hegemonia'. No sistema hegemônico, existe democracia entre o grupo dirigente e os grupos dirigidos na medida em que o desenvolvimento da economia, e, por conseguinte da legislação, que exprime este desenvolvimento, favorece a passagem (molecular) dos grupos dirigidos ao grupo dirigente.

No Brasil, essa vinculação entre democracia e hegemonia encontra possibilidade de se viabilizar com a promulgação da Constituição de 1988, que representa o marco da legalização e legitimação do princípio da participação da sociedade nas ações estatais; relevante vetor para o estabelecimento de novas bases de relação entre Estado e sociedade. Destaque- 
se que a legitimação da participação social é, ao mesmo tempo, base e consequência do processo de democratização do país, iniciado com a abertura política no final do governo militar, entre os anos de 1974 e 1979, numa conjuntura de recessão econômica e de lutas sociais contra o regime.

A abertura política tem íntima relação com a "queda de braço" travada entre o Estado, predominantemente coercitivo e representado pelo governo militar, e os aparelhos privados de hegemonia da sociedade civil, mobilizados para destituí-lo do poder, num momento de agravamento da crise do modelo econômico que o sustentava. Em razão disso, o regime sofre uma "inflexão para baixo" e se vê compelido a desencadear o processo de abertura política como estratégia de sobrevivência (NETTO, 2010, p. 41). Isto, numa manifesta situação de correlação de força com o protagonismo da sociedade civil, que emergia de uma condição de retração política, imposta pela ditadura, para a de sujeito, na luta política pelo restabelecimento da democracia.

Esse cenário remete para o que Gramsci (1984, p. 149) preceitua sobre o funcionamento do Estado como unidade orgânica ampliada, pois, conforme explica: "[...] na noção geral de Estado entram elementos que também são comuns à noção de sociedade civil (neste sentido, poder-se-ia dizer que Estado = sociedade política + sociedade civil, isto é, hegemonia revertida de coerção)." De acordo com as reflexões de Coutinho (1992, p. 128), o emprego dessa fórmula à realidade brasileira não cabe no momento histórico da Ditadura Militar, nem no anterior a ela, quando o Brasil apresentava um modelo de Estado com predominância do caráter "oriental". Este, definido por Gramsci (1984) como aquele que detém o controle sobre tudo numa sociedade civil dita "primitiva e gelatinosa", diferentemente do modelo de tipo "ocidental" aquele em que se estabelece uma "justa relação entre Estado e sociedade civil", na qual essa se apresenta com feição forte e hodierna.

É só com a evolução do processo democrático que se vislumbra a formação do caráter ocidental do Estado brasileiro, já que, seguindo o que Gramsci sustenta, a "ocidentalidade de uma formação social é resultante de um processo histórico." (COUTINHO, 1992, p. 129). Assim, o processo de redemocratização do país representa um momento histórico no qual se abrem possibilidades para um Estado "ampliado". Este leva ao fortalecimento da estrutura da sociedade civil (movimentos sociais, associações, partidos políticos, sindicatos etc.), necessário para a construção gradativa de um ambiente político, econômico, social e cultural favorável ao estabelecimento de um sistema hegemônico que, como diz Gramsci (1984), só opera em estrutura democrática. Esse ambiente, construído de forma gradativa, remete ao que o pensador preconiza sobre "guerra de posição", traduzida, grosso modo, como a ocupação estratégica e gradual dos espaços de poder, diferentemente da "guerra de movimento", cujo pressuposto é tomar de assalto o poder. 
Contudo, a conformação de um caráter ocidental da sociedade civil brasileira encontra barreiras no passado, com o regime antiparticipativo instalado pela Ditadura Militar; no presente, diante da estruturação de um modelo de sociedade guiada pelo ideário neoliberal, que valoriza especialmente as liberdades individuais e as regras de mercado, arrefecendo ou mesmo paralisando as forças políticas da sociedade civil. Nessa trajetória, entremeada pela abertura democrática, os movimentos sociais recebem diferentes conceitos e assumem configurações diversas, de acordo com cada contexto sociopolítico, com muitos deles atuando distantes da órbita do pensamento gramsciano (DURIGUETTO, 2007).

Como mostram Montaño e Duriguetto (2011), entre os anos de 1964 e 1970, no contexto do governo militar, os movimentos sociais atuavam predominantemente na luta política contra a ditadura e, em face do projeto de redemocratização do país, a partir dos anos de 1980 passam a participar da luta por direitos políticos e sociais. O Movimento "Diretas Já" é emblemático na luta por direitos políticos no Brasil. Organizado entre os anos de 1983 e 1984, mobilizou milhões de brasileiros, de vários segmentos sociais, para reivindicar a reinstauração das eleições diretas no Brasil, interrompida pela Ditadura Militar. A proposta foi apresentada ao Congresso Nacional através da Emenda Constitucional do Deputado Federal, pelo PMDB, Dante de Oliveira, mas prevaleceu a vontade das forças conservadoras do Congresso, que não a aprovou, adiando as eleições diretas para o ano de 1989. Contudo, teve como saldo positivo o retorno do governo civil, em 1985, e a promulgação da nova Constituição Federal em 1988 (RODRIGUES, 2003).

Nesse ambiente democrático em construção, embora sem operar em patamar elevado e diante de um aparato midiático empenhado em influenciar os eleitores, muitos exercendo pela primeira vez o voto direto, a população brasileira elege, em 1989, Fernando Collor de Melo para presidente do Brasil. Era um candidato com histórico político de matriz conservadora, que conseguiu resultado vitorioso por se apresentar com roupagem e discurso de "justiceiro" diante de um Estado que priorizava as elites econômicas, que ele intitulava de "marajás". Com Collor na presidência, o caminho aberto pela luta de partidos e organizações sociais em direção à construção de um modelo estatal próximo ao ideário gramsciano, de Estado ampliado, encontra barreiras no seio do próprio Estado. Este, alinhado com as imposições do capitalismo global operante, adota o modelo neoliberal de diminuição do Estado e valorização do mercado.

Analisando esse cenário à luz da concepção de sociedade civil de Gramsci, que a põe como conteúdo ético do Estado e como base material para a conquista de hegemonia (COUTINHO, 1992), os movimentos sociais no Brasil dos anos de 1990 não encontram ambiente político favorável para avançarem nessa direção. É que vivem um contexto de organização e consolidação do projeto político neoliberal, pelo qual são transferidas res- 
ponsabilidades antes do Estado para a sociedade civil. Isto em contraposição a um projeto político democratizante para o país, que vislumbra o aprofundamento democrático e a construção de novas bases de relação entre Estado e sociedade. Tendo, como princípio central, a participação ativa da sociedade, compreendida como atuação direta dos sujeitos políticos nos processos decisórios, um ingrediente essencial ao aprimoramento do jogo democrático (DURIGUETTO, 2007).

Mesmo sob hegemonia do projeto político neoliberal, a atitude de colocar a sociedade civil como conteúdo ético do Estado é nela sentida quando diversos grupos se mobilizam, em 1992, contra o impeachment do Presidente Fernando Collor, tendo à frente um movimento de massa liderado pelo movimento estudantil, denominado "Caras Pintadas", por pintarem os rostos com as cores da bandeira brasileira. Isso faz despontar uma ação política da sociedade civil para a impugnação do Presidente da República, principalmente devido às denúncias de corrupção no seu governo e à implantação de uma política econômica de recessão em atendimento ao receituário neoliberal. As manifestações públicas, que resultaram no impeachment de Fernando Collor, foram favorecidas pelo ambiente democrático garantido pela Constituição de 1988, que pôs a democracia como principal fundamento e estabeleceu o princípio da participação social como direito ${ }^{1}$.

Ressalte-se que, dentro dos marcos do neoliberalismo, fortalecidos no Governo Fernando Henrique Cardoso (1995-2000), os intelectuais orgânicos, vinculados a essa corrente ideológica, sublinham a sociedade civil como homogênea e sem conflitos, figurando apenas no espaço privado. $\mathrm{O}$ Estado, reduzido ao mínimo, apresenta-se neutro e acima das classes sociais (NOGUEIRA, 2011). Nesse contexto, a relação Estado/sociedade não se estabelece coincidindo com a concepção de Gramsci, na qual não há separação entre sociedade civil e sociedade política, mas uma relação orgânica e dialética.

Dadas as condições democráticas asseguradas pela Constituição Federal, a construção de uma relação de consenso entre Estado e sociedade, conforme o ideário gramsciano, encontra ambiente favorável na reconfiguração da esfera pública brasileira. Nesse cenário, ela tem a perspectiva de tomar a direção, apresentada por Hannah Arendt (1997), de espaço público ampliado, de exercício da cidadania e de visibilidade em comum.

É nesse espaço público reconfigurado que se vislumbra a possibilidade de uma ação política dos movimentos sociais vinculada ao projeto democratizante, enquanto expressões da sociedade civil, que se organizam não só para reivindicar demandas perante o Estado, mas também para exercer influência na transformação do sistema socioeconômico hege-

${ }^{1} \mathrm{O}$ direito à participação social encontra-se explicitado na Constituição Federal nos seguintes artigos: Art. 1\%, parágrafo único; Art. 14, incisos I, II e II; Art. 27, parágrafo 4; Art. 29, incisos XII e XIII; Art. 61, parágrafo 2º; Art. 194, parágrafo único, inciso VII; Art. 204, inciso II; Art. 227, parágrafo 1ำ (AVRITZER et al., 2008). 
mônico (LOJKINE, 1981, p. 298). Nesse processo de luta por hegemonia, engendrado pelos movimentos sociais e permitido pela democratização do espaço público, é dada à sociedade brasileira a possibilidade de experienciar o exercício do controle social das ações públicas como

possibilidade de o Estado (que não é neutro, embora objetive a igualdade jurídico-política e socioeconômica) ser controlado pelos mais diversos grupos sociais que conflitam na sociedade. Esses grupos, embora tenham agendas e interesses distintos, podem controlar o Estado - o que implica controlarem-se mutuamente, tendo em vista o caráter democrático e republicano de suas instituições e dos fundamentos que o erigem. (FONSECA; BEUTTENMLLER, 2007, p. 76).

Essa concepção de controle social passa a frequentar o debate contemporâneo na sociedade brasileira ao longo da década dos anos 2000, em presença do confronto entre o projeto democratizante para o país com a perspectiva neoliberal de reforma do Estado, que se põe a serviço do fortalecimento do capitalismo. No bojo desses dois processos políticos, a relação entre Estado e sociedade civil assume contornos distintos: um que vislumbra uma relação orgânica e de disputa por hegemonia entre Estado e sociedade, ligada ao pensamento gramsciano de Estado ampliado; e outra vinculada à perspectiva do neoliberalismo, pela qual sociedade política e sociedade civil são dimensões opostas, com o Estado se sobrepondo às classes sociais em favor dos interesses da economia global (PEREIRA et al., 1999).

Nesses distintos processos políticos, um de ajuste neoliberal e outro de aprofundamento democrático, a prática do controle social das ações do Estado sofre um desvio conceitual visível, especialmente na gestão de políticas públicas. Nesse campo, mesmo com a criação de espaços de participação social na gestão das políticas, via conselhos gestores, emanam interesses diversos que influenciam a prática do controle social direcionando-a para contemplar, principalmente, os ditames dos grupos dominantes e menos os interesses das classes subalternas (DAGNINO, 2004). Desse modo, a sociedade civil brasileira apresenta-se com a marca social liberal de neutralidade de classe, embotando a característica que lhe é atribuída pela concepção gramsciana de campo de disputa política entre as classes sociais (SIMIONATTO, 2010).

Retomando a concepção gramsciana de hegemonia, traduzida por Cerroni (1982) como a capacidade de uma classe, atuando por meio de consenso, sobrepor seus interesses e valores ao conjunto da sociedade, é na esfera pública que a sociedade civil, no Brasil atual, encontra maior espaço para o controle democrático das ações do Estado e para a conquista de poder hegemônico. Um espaço que vem se ampliando com a evolução das tecnologias da informação, abrindo caminho para a construção de um projeto societário que vislumbre a conquista de hegemonia pelas classes subalternas. Um caminho nada fácil frente às formas de domínio e explo- 
ração do capitalismo contemporâneo, sem deixar de considerar uma esfera pública onde atuam uma multiplicidade de grupos sociais e indivíduos distintos com interesses diversos e antagônicos, tanto de caráter coletivo quanto privado.

\section{Participação e controle social na era informacional}

Na sociedade contemporânea, fortemente marcada pela revolução informacional ${ }^{2}$, assim como na realidade brasileira, a construção de uma relação dialética entre Estado e sociedade vem sendo favorecida pelo avanço e pela utilização das tecnologias da informação. Estas possibilitam o alargamento da ação política dos movimentos sociais pela formação de redes de articulação entre si, em dimensão local e global. As tecnologias da informação também favorecem a participação direta da sociedade civil no controle social das ações estatais, com destaque para a utilização da internet como ferramenta de publicização de informações aos cidadãos sobre a gestão pública, a partir da implantação do governo eletrônico, ou egoverno ${ }^{3}$.

A internet é, sem dúvida, um espaço aberto, na sociedade do globalismo informacional, para a transparência pública. Mas, conforme destaca Lojkine (2002, p. 149), tanto pode gerar "[...] uma verdadeira revolução organizacional, que promova o acesso de todos e todas as informações e por consequência o autogoverno dos homens", quanto pode ser utilizada numa concepção elitista de reserva de informação pelos grupos dirigentes, em favor de sua hegemonia.

No Brasil, que tem a democracia representativa como forma de organização da sociedade, na qual o voto prevalece como mecanismo de participação, a internet é uma ferramenta que contribui para a democratização da informação e para o alargamento da prática política de sujeitos sociais, individuais ou coletivos, para o controle democrático das ações do Estado e seu direcionamento para o alcance dos interesses coletivos.

Um exemplo disso foi a aprovação da Lei da Ficha Limpa (Lei Complementar $\mathrm{n}^{\circ}$. 135/2010). Trata-se de uma lei de iniciativa popular, apresentada ao Congresso Nacional, com respaldo na Constituição de 1988, que estabelece regras mais rígidas para que políticos condenados pela justiça sejam impedidos de concorrer a mandatos eletivos (BRASIL, 2010). Pelos preceitos constitucionais, a aprovação da lei dependeria da assinatura de

\footnotetext{
${ }^{2}$ Diz respeito a um conjunto de mutações ocorridas no campo tecnológico e do conhecimento, que produz efeitos significativos, para o bem e para o mal, no modelo de produção, nas relações de trabalho, nos hábitos culturais e nos sistemas de valores e percepções humanas (CASTELLS, 1999; LOJKINE, 2002).

${ }_{3}^{3}$ Pinho (2008) define e-governo como a informatização das atividades internas do governo, de comunicação com cidadãos, com setores da sociedade e do próprio governo, através de portais governamentais disponíveis na rede mundial de computadores e que impactam na transparência das ações do Estado.
} 
$1 \%$ do eleitorado brasileiro, num universo de 135,8 milhões $^{4}$ de eleitores. Para atingir esse percentual, a internet foi um instrumento fundamental: por ela foram colhidas milhões de assinaturas eletrônicas nas redes sociais e sítios virtuais, proporcionando o alargamento do espaço público brasileiro e o estreitamento dos canais de comunicação, de pressão e controle entre sociedade civil e sociedade política.

Contudo, a funcionalidade da transparência, por meio da internet, para um controle social efetivo das ações do Estado, tem como grande limitação a exclusão digital. Como afirma Balboni (2007, p. 38), "a exclusão digital no Brasil acompanha o cenário de exclusão social do país". A pesquisa de Balboni (2007) revela as desigualdades de renda e de educação como grandes empecilhos para o acesso aos serviços de internet, posto que a população de baixa renda e baixa escolaridade possui pouca ou nenhuma familiaridade com o uso da informática e por isso tem acesso limitado à rede mundial de computadores.

Apesar da exclusão digital, a sociedade brasileira tem vivenciado grandes manifestações de massa, como as jornadas de junho de 2013, em São Paulo. Elas foram mobilizadas pelas redes sociais na internet por jovens estudantes, reunindo milhares de pessoas contra o aumento das tarifas de transportes urbanos, sendo disseminadas para a maioria das capitais e cidades e incorporando diversas outras demandas, principalmente a precariedade dos serviços públicos e o combate à corrupção ${ }^{5}$. Nesse cenário, foram evidenciadas as formulações teóricas de Gramsci (1984) de que o Estado opera tanto pelo uso de aparatos coercitivos quanto pela busca do consenso. Tomando como exemplo as jornadas de junho de 2013, os manifestantes tornaram visíveis, pelo exercício da democracia direta e por meio de divulgação no espaço virtual, as insatisfações, contradições e heterogeneidades da sociedade civil, que levaram o Estado brasileiro a adotar uma conduta tanto coercitiva quanto de busca por consenso. No primeiro caso, a sociedade política, representada pela Polícia Militar, agiu por meio da violência e criminalização dos manifestantes; posteriormente, sob pressão popular, pela busca de consenso, com as demandas da sociedade tendo ressonância nos poderes Executivo, Legislativo e Judiciário que, com legitimidade abalada, viram-se obrigados a dar resposta imediata a algumas delas.

A ida da população às ruas, promovendo o alargamento do espaço público e o exercício da democracia direta, indica que o processo de democratização na sociedade brasileira vem conseguindo alcançar patamar mais elevado. A ampla mobilização e a publicização das manifestações pelas redes sociais, no espaço virtual, deram visibilidade à correlação de forças, presente no constructo teórico gramsciano, que se trava entre os grupos dominantes e a população que ocupa as ruas. Ficou visível tanto a busca

\footnotetext{
${ }^{4}$ Dado disponível em: <http://www.tse.jus.br/eleicoes/estatisticas/evolucao-do-eleitorado>.

${ }^{5}$ Dados disponíveis em: <http://pt.wikipedia.org/wiki/Manifestações_no_Brasil_em_2013>.
} 
por consensos quanto a presença de práticas coercitivas que atravessam a relação entre sociedade civil e sociedade política, com a primeira atuando para fazer valer seus interesses e criar e garantir direitos perante a sociedade política. Essa, por sua vez, utilizando-se do seu poder de força, lança mão de seus aparelhos coercitivos, dentre os quais a violência física e, devido à pressão do poder de mobilização das ruas, também toma medidas que levam à socialização da política, ou seja, à aproximação entre a sociedade civil e o Estado. Uma iniciativa nessa direção foi tomada pelo Poder Executivo, quando a Presidente da Republica reuniu ministros, gestores públicos e representantes de movimentos sociais para propor um pacto com "as vozes que vêm das ruas", conforme expôs no seu discurso ${ }^{6}$, para dar respostas às questões que mobilizaram a população brasileira, em junho de 2013, com destaque para a realização da reforma política: melhorar a qualidade do transporte público, da saúde e da educação.

Apesar da assimetria entre os discursos e as práticas do governo brasileiro, as propostas e iniciativas adotadas na dimensão da sociedade política, nos momentos históricos de luta e mobilizações protagonizadas pela sociedade civil, do impeachment do Presidente Fernando Collor aos protestos de rua atuais, demonstram que, mesmo em condições bem distintas da realidade vivida por Gramsci, o seu aparato teórico de defesa da vitória do consenso e da democracia como principal força criadora (COUTINHO, 1998), contribui para reflexão e compreensão da realidade brasileira mais recente. Além disso, para o quanto ainda se tem que avançar para alcançar um patamar mais qualitativo de participação social no controle do Estado em direção à socialização da política. Esta, expressa na dialética gramsciana como aquele ponto em que se desfaz a dicotomia entre Estado e sociedade civil, construindo um projeto societário no qual o consenso se sobrepõe à coerção e os interesses coletivos suplantam os interesses privados da classe dominante.

\section{Considerações finais}

As concepções teóricas de Gramsci firmam-se como referência de análise e interpretação da realidade contemporânea brasileira com a abertura do processo de democratização do Brasil, fruto das lutas sociais contra a Ditadura Militar. A Constituição de 1988, que tem a democracia como principal fundamento, representa o marco da legitimação e legalização da participação da sociedade no controle das ações do Estado. Cria, também, um ambiente favorável à construção de um modelo de Estado que, como Gramsci (2005a) preceitua, funciona como unidade orgânica

\footnotetext{
${ }^{6}$ Disponível em: <http://www2.planalto.gov.br/imprensa/discursos/discurso-da-presidenta-da-republica-dilmarousseff-durante-reuniao-com-governadores-e-prefeitos-de-capitais>.
} 
ampliada da qual a sociedade civil é parte integrante, sua dimensão ética e base material para a luta por hegemonia.

Nesse cenário, a influência do pensamento gramsciano no quadro analítico de atuação dos movimentos sociais, participando do controle das ações do Estado, segue por vias interpretativas distintas; uma vinculada ao projeto político neoliberal e outra, ao projeto político de aprofundamento democrático, que se contrapõem como ideologias orientadoras do funcionamento da sociedade brasileira. As concepções de sociedade civil e de Estado, apresentadas por Gramsci (1984; 2005a), sofrem desvios conceituais no quadro interpretativo dos intelectuais orgânicos que defendem a ideologia neoliberal, hegemônica no Brasil desde os anos 1990. Nessa visão, a sociedade civil é chamada a atuar com papel complementar à atuação do Estado mínimo, operando de forma despolitizada, por interesses individuais, corporativos e setoriais.

No projeto político democratizante, os movimentos sociais compõem a dimensão da sociedade civil, concebida como espaço de lutas democráticas e por direitos, alinhados ao referencial gramsciano. Possuem o papel político de fortalecer o processo democrático por meio de práticas políticas que ampliam a participação da sociedade e seu poder de decisão política, na perspectiva da transformação social, ou seja, da hegemonia do poder político pelas classes subalternas. Situados no contexto da revolução das tecnologias da informação, a internet vem se constituindo como ferramenta importante para o alargamento da ação política dos movimentos sociais, num espaço público de dimensão mundial. Pois, fazendo uso de redes sociais, sites e navegadores móveis, eles se mobilizam e se articulam entre si e com o aparato estatal. O espaço público virtual possibilita a publicização e transparência do Estado brasileiro. Além disso, contribui para a democratização da informação, facilitando o controle das ações estatais pela sociedade e vice-versa, embora também seja útil como reserva de informação e de poder pelas classes dominantes, para preservar sua hegemonia, favorecida pela exclusão digital. Esta, no Brasil, se dá na mesma proporção da exclusão social.

Nas condições históricas do século XXI, nas quais a materialização das ideias de Gramsci (1984) de Estado ampliado encontram barreiras ideológicas que dificultam o estabelecimento de uma relação mais justa entre o aparato estatal e sociedade, as manifestações e lutas políticas dos movimentos sociais, no Brasil, contribuem para avistar, à luz do pensamento gramsciano, alternativas contra a alienação da sociedade e a favor da construção de relações dialéticas entre sociedade política e sociedade civil, tendo o consenso como base. 


\section{Referências}

ARENDT, H. As esferas pública e privada. In: A condição humana. Rio de Janeiro: Forense Universitária. 1997.

AVRITZER, L. et al. (org.). Corrupção: ensaios e criticas. Belo Horizonte: UFMG. 2008.

BALBONI, M. R. Por detrás da inclusão digital: uma reflexão sobre o consumo e a produção de informação em centros públicos de acesso à internet no Brasil. 2007. Tese (Doutorado em Interfaces Sociais da Comunicação) Escola de Comunicações e Artes, Universidade de São Paulo. 2007. Disponível em: <http://www.teses.usp.br/teses/disponiveis/27/27154/tde10102007-120815/>. Acesso em: 17 set. 2012.

BIANCHI, A. O laboratório de Gramsci: filosofia, história e política. São Paulo: Alameda. 2008.

CASTELLS, M. A sociedade em rede: a era da informação: economia, sociedade e cultura. São Paulo: Paz e Terra. 1999.

CERRONI, U. Teoria do partido político. São Paulo: Ciências Humanas. 1982. COUTINHO, C. N. Gramsci: um estudo sobre seu pensamento político. Rio de Janeiro: Campus. 1992.

. Socialismo e democracia: a atualidade de Gramsci. In: AGGIO, A. (org). Gramsci: a vitalidade de um pensamento. São Paulo: Unesp. 1998.

DAGNINO, E. Sociedade civil, participação e cidadania: de que estamos falando? In: MATO, D. (coord.). Políticas de ciudadanía y sociedad civil en tiempos de globalización. Caracas: Faces; Universidad Central de Venezuela. 2004.

DURIGUETTO, M. L. Sociedade civil e democracia: um debate necessário. São Paulo: Cortez. 2007.

FONSECA, F.; BEUTTENMULLER, G. Democracia, informação e controle social: reflexões conceituais e o papel dos Observatórios Locais. In: FONSECA, F. C. P.; GUEDES, A. M. (org.). Controle social da administração pública. São Paulo: Unesp (Cultura Acadêmica). 2007.

GRAMSCI, A. Intelectuais e a organização da cultura. São Paulo: Civilização Brasileira. 1982.

- Maquiavel, a política e o Estado moderno. Rio de Janeiro: Civilização Brasileira. 1984.

. In: COUTINHO, C. N.; HENRIQUES, L. S. (org.). Cartas do cárcere, 1926-1930, v. 1. Rio de Janeiro: Civilização Brasileira. 2005a.

. In: COUTINHO, C. N.; HENRIQUES, L. S. (org.). Cartas do cárcere, 1931-1937, v. 2. Rio de Janeiro: Civilização Brasileira. 2005 b. 
HOBBES, T. Leviatã ou matéria, forma e poder de um Estado eclesiástico e civil. São Paulo: Abril Cultural. 1979.

LOCKE, J. Dois tratados sobre o governo. São Paulo: Martins Fontes. 2001.

LOJKINE, J. O Estado capitalista e a gestão urbana. São Paulo: Martins Fontes. 1981.

. A revolução informacional. São Paulo: Cortez. 2002.

MARX, K. A ideologia alemã (Feuerbach). São Paulo: Hucitec. 1993.

MARX, K.; ENGELS, F. A guerra civil na França: crítica ao Programa de Gotha. Ridendo Castigat Mores. 1999. Disponível em: <http://www.ebooksbrasil. org/adobeebook/guerracivil.pdf>. Acesso em: 15 set. 2014.

MONTAÑO, C.; DURIGUETTO, M. L. Estado, classe e movimento social. São Paulo: Cortez. 2011.

NETTO, J. P. Ditadura e serviço social: uma análise do serviço social no Brasil pós-64. São Paulo: Cortez. 2010.

NOGUEIRA, M. A. Um Estado para a sociedade civil: temas éticos e políticos da gestão democrática. São Paulo: Cortez. 2011.

PINHO, J. A. G. de. Investigando portais de governo eletrônico de estados no Brasil: muita tecnologia, pouca democracia. Revista de Administração Pública, v. 42, n. 3, maio./jun. 2008.

PEREIRA, L. C. B. et al. (org.). O público não-estatal na reforma do Estado. Rio de Janeiro: Fundação Getúlio Vargas. 1999.

RODRIGUES, A. T. Diretas Já: o grito preso na garganta. São Paulo: Fundação Perseu Abramo. 2003.

ROUSSEAU, J. J. Do contrato social ou princípios do direito político. São Paulo: Abril Cultural. 1978.

SECCO, L. Gramsci e o Brasil: recepção e difusão de suas ideias. São Paulo: Cortez. 2002.

SIMIONATTO, I. Razões para continuar utilizando a categoria sociedade civil. In: CANTOIA LUIZ, D. E. (org). Sociedade civil e democracia: expressões contemporâneas. São Paulo: Veras Editora. 2010.

Gramsci: sua teoria, incidência no Brasil, influência no serviço social. São Paulo: Cortez. 2011.

SINGER, P. A crise do milagre. São Paulo: Paz e Terra. 1989.

Recebido em 15 de setembro de 2014 Aprovado para publicação em 08 de maio de 2015. 